\title{
AVALIAÇÃO DA SUSTENTABILIDADE AMBIENTAL DE SISTEMAS AGROPECUÁRIOS EM MICROBACIAS DO NORDESTE PARAENSE A PARTIR DE PARÂMETROS FÍSICO-QUÍMICOS.
}

Daniel Fernandes Rodrigues BARROSO ${ }^{1}$ Ricardo de Oliveira FIGUEIREDO ${ }^{2}$; Camila da Silva PIRES ${ }^{3}$; Fabíola Fernandes COSTA ${ }^{4}$.

1. Programa de Pós-graduação em Ciências Ambientais. Universidade Federal do Pará - Rua Augusto Correa, 01 - Guamá. CEP: 66075-11, Belém-PA. E-mail: daniel.ferbarroso@gmail.com

2. Embrapa Meio Ambiente. Rodovia SP-340, Tanquinho Velho, CEP: 13820-000, Jaguariúna- SP. E-mail: ricardo.figueiredo@embrapa.br

3. Programa de Pós-graduação em Ciências Ambientais. Universidade Federal do Pará - Rua Augusto Correa , 01 - Guamá. CEP: 66075-11, Belém-PA. E-mail: camilapires@ymail.com

4. Programa de Pós-graduação em Química. Universidade Federal do Pará - Rua Augusto Correa , 01 - Guamá. CEP: 66075-11, Belém-PA. E-mail: fabiolaffc@yahoo.com.br

\section{RESUMO}

O Nordeste Paraense é caracterizado por conter as mais antigas áreas de colonização da Amazônia, onde atualmente predomina a agricultura familiar itinerante de derruba e queima e também a pecuária bovina extensiva. A paisagem é fortemente marcada pela vegetação secundária em diversos estágios de sucessão e poucos remanescentes de floresta primária, a qual é geralmente localizada às margens de pequenos rios e igarapés. Nesse contexto, o presente estudo, conduzido em 14 microbacias no Nordeste Paraense sob diferentes usos e cobertura da terra e em quatro microbacias em áreas florestais sob baixo impacto antrópico, objetivou avaliar a sustentabilidade ambiental de atividades agropecuárias baseados em parâmetros físico-químicos de qualidade de água. Verificou-se uma forte influência dos sistemas agropecuários, especialmente as pastagens, sobre os parâmetros físico-químicos mensurados, com redução da concentração de oxigênio dissolvido, e aumento da temperatura, do $\mathrm{pH}$ e da condutividade elétrica. Pelo presente estudo, infere-se que a mata ciliar tem grande potencial para mitigar os impactos dos sistemas agrícolas nos recursos hídricos e deve ser priorizada na gestão de bacias. Adicionalmente, sugere-se os parâmetros acima listados como indicadores de sustentabilidade ambiental dos sistemas agropecuários de produção para a gestão local de bacias.

Palavras-chave: Parâmetros físico-químicos; Sustentabilidade Ambiental, Nordeste Paraense.

\footnotetext{
${ }^{1}$ Eixo temático: Planejamento, ordenamento territorial e ambiental de bacias hidrográficas.
} 


\begin{abstract}
The Para Northeast is characterized as the oldest settlement region of the Amazon, dominated by smallholders slash and burn agriculture and also the extensive cattle raising. The landscape is strongly marked by secondary vegetation in various stages of succession and a few remnant forests, usually located in the riparian zones of small rivers and streams. In this context, this study, was conducted in 14 watersheds in Para Northeast under different land uses and land cover and in four watersheds in forest areas under low human impact, and aimed to evaluate the environmental sustainability of agricultural activities based on the physicochemical parameters of water. It was observed a strong influence of agricultural systems, especially pastures, on the measured parameters, with reduction of dissolved oxygen concentration, and increase of temperature, $\mathrm{pH}$ and electrical conductivity. By this study, it can be inferred that the riparian vegetation has the potential to mitigate agricultural systems impacts on water resources and must be prioritized in watershed management. Additionally we suggested the parameters above listed as indicators of environmental sustainability of agricultural production systems for local watersheds management.
\end{abstract}

Keywords: Physicochemical parameters; Environmental sustainability, Northeast of Pará.

\title{
1. INTRODUÇÃO
}

O bioma amazônico é caracterizado por densa floresta tropical úmida que possui uma enorme biodiversidade, abundância de águas fluviais e muitas riquezas minerais no seu subsolo.

Atualmente a cobertura do solo na Amazônia é dominada por três tipos de paisagem: floresta primária, floresta secundária (capoeiras em diversos estágios de sucessão) e pastagem (SALIMON, 2003). Localizado na Amazônia oriental, a mesorregião denominada como Nordeste Paraense é caracterizada por atividades agropecuárias (MOREIRA, 2008), principalmente a agricultura familiar itinerante com derruba e queima da vegetação secundária ou de pousio (localmente denominada como capoeira) e também pela formação de amplas pastagens. Watrin, Gerhard e Maciel (2009) analisaram a dinâmica do uso da terra e a configuração da paisagem em três bacias hidrográficas no Nordeste Paraense (Igarapé São João, Igarapé Cumaru e Igarapé Timboteua com áreas 2.599,11 ha, 4.163,04 ha e 7.628,13 ha, respectivamente), em antigas áreas de colonização de base econômica familiar e concluíram que as áreas de floresta secundária em estágios sucessionais iniciais são mais representadas em duas das três bacias, e que as pastagens representam o padrão dominante de uso da terra em todas as três bacias, com predominâncias da classe pasto sujo.

Neste contexto o presente estudo tem como objetivo avaliar a sustentabilidade ambiental de atividades agropecuárias em 14 microbacias no Nordeste Paraense, cujas áreas variam de 22 a 149 ha, baseados em parâmetros físico-químicos de qualidade de água (pH, OD, CE e T). 


\section{MATERIAIS E MÉTODOS}

\subsection{CARACTERIZAÇÃO DA ÁREA DE ESTUDO}

A localização da área de estudo no Nordeste Paraense pode ser observada na Figura 1. As mesobacias dos igarapés contíguos Buiúna e Timboteua (8.756 ha) e do Igarapé Peripindeua (15.000 ha) foram o foco central das ações do Projeto Gestabacias, cujas pesquisas visaram balizar a gestão dos recursos naturais nessas duas áreas. A primeira é denominada como a Área 1 e ocupa área dos municípios de Marapanim e Igarapé-Açú. A segunda foi denominada como Área 3 e ocupa áreas dos municípios de Irituia e Mãe do Rio. Por outro lado, como áreas de referência para comparação das alterações encontradas nas mesobacias avaliadas foram definidas as áreas 2 e 4, que apresentam florestas relativamente preservadas e localizam-se respectivamente nos municípios de São Francisco do Pará e Capitão-Poço.

Figura 1. Localização da área de estudo.

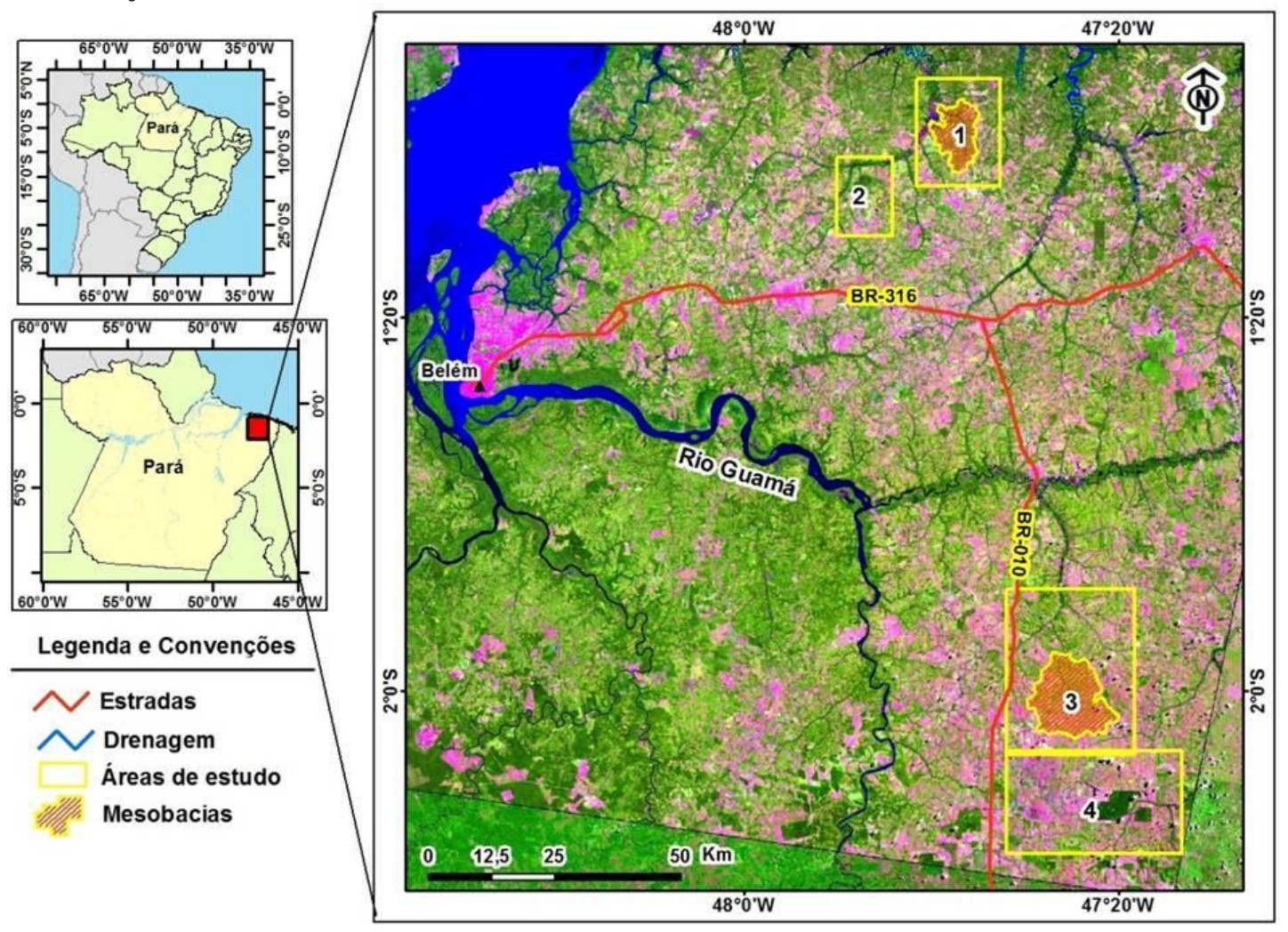

Para a análise das características ambientais das áreas estudadas, as duas mesobacias correspondentes às áreas 1 e 3 foram segmentadas em microbacias com a utilização da ferramenta SWAT2000 (DI LUZIO et al., 2002), tendo como base a hidrografia digitalizada de cartas topográficas em escala 1:100.000. Esta delimitação foi baseada em um Modelo Digital de Elevação do Terreno (MDT) determinado a partir de dados da Shuttle Radar Topography Mission - SRTM. As análise foram feitas de modo a produzir microbacias com áreas entre dezenas e poucas centenas de hectares (entre 20-350 hectares). O predomínio de uma classe de uso da terra foi determinado a 
partir da inspeção visual de limite das microbacias sobreposto a composições coloridas (baseadas em imagens de Satélite Landsat, sensor TM, RGB345) sobre as áreas das mesobacias, além da checagem de campo.

A seleção das microbacias para avaliação pelo presente estudo ocorreu no período de junho a agosto de 2009. Durante as campanhas de campo para realização desta seleção de microbacias, os seguintes aspectos foram observados: o acesso para facilitar a logística dos trabalhos de campo e características físicas do ambiente como a área de drenagem de cada microbacia, os usos da terra predominantes em cada uma delas e a análise preliminar de parâmetros físico-químicos (temperatura, $\mathrm{pH}$, oxigênio dissolvido e condutividade elétrica) nas águas desses riachos para avaliar as respostas dos igarapés às mudanças de uso da terra.

Foram definidas as seguintes classes de uso e cobertura nas microbacias: floresta, pastagem, capoeira alta, capoeira baixa, vegetação de várzea, cultivo agrícola, solo exposto e habitações.

As microbacias pertencentes a bacia do rio Marapanim foram codificadas como M1, M2, M3, M4, M5, M6, M7, MR1 e MR2. Por outro lado, as microbacias pertencentes a bacia do rio Guamá foram codificadas com G1, G2, G3, G4, G5, G6, G7, GR1 e GR2.

\subsection{GERAÇÃO E ANÁLISE DOS DADOS}

As campanhas de campo foram realizadas mensalmente no período de outubro de 2009 a setembro de 2010, perfazendo doze campanhas para medições de parâmetros físico-químicos.

Para a obtenção dos valores do potencial hidrogeniônico - $\mathrm{pH}$ - foram realizadas medições através do método potenciométrico usando-se aparelho digital (eletrodo combinado de vidro e calomelano, com correção de temperatura para $25^{\circ} \mathrm{C}$ ), da marca ORION, modelo $290 \mathrm{~A}$ plus. A calibração do peagâmetro foi realizada imergindo o eletrodo de vidro em soluções-tampão de $\mathrm{pH}$ 4, 5 e 7 (CETE5B, 1978).

Para oxigênio dissolvido (OD) e temperatura (T) foi utilizado o oxímetro Y5I® 55, que por meio de uma sonda polarográfica de compensação automática de temperatura, permite quantificação da concentração de oxigênio dissolvido com elevada precisão e a temperatura simultaneamente.

Por sua vez, para a condutividade elétrica (CE), o método aplicado foi o condutimétrico (CETESB, 1978), com o equipamento portátil digital VWR® (modelo 2052).

Para todas essas medidas os sensores dos equipamentos foram mergulhados no centro da corrente do igarapé a uma profundidade variando de 10 a $20 \mathrm{~cm}$.

Por fim, para verificação da relação entre os parâmetros físico-químicos e o uso e cobertura da terra nas microbacias foi aplicada correlação de Spearman, onde as variáveis analisadas foram correlacionadas com os percentuais de uso e cobertura da terra nas microbacias. 
Foram também calculadas e observadas em gráficos tipo "boxplot" as métricas estatísticas mediana, média, interquartis, máximos, mínimos e valores extremos (outliers) dos parâmetros físico-químicos avaliados.

\section{RESULTADOS E DISCUSSÃO}

Com base nos dados coletados por meio das medidas de campo e posterior análise estatística, são apresentados na Tabela 1 os resultados obtidos e discutidas as implicações destes em relação aos objetivos desta pesquisa.

Tabela 1 - Valores médios e erros-padrão dos parâmetros físico-químicos medidos nos igarapés das microbacias avaliadas neste estudo e suas respectivas áreas de drenagem e uso da terra da terra predominante.

\begin{tabular}{ccccccc}
\hline \multirow{2}{*}{ MICROBACIA } & \multicolumn{5}{c}{ PARÂMETROS } \\
\cline { 2 - 7 } & $\begin{array}{c}\text { Área } \\
\text { (ha) }\end{array}$ & $\begin{array}{c}\text { Uso da terra } \\
\text { predominante }\end{array}$ & pH & T $\left({ }^{\circ} \mathbf{C}\right)$ & OD $(\boldsymbol{\%})$ & CE $(\boldsymbol{\mu S})$ \\
\hline M1 & 37,55 & Agropecuária & $4,47( \pm 0,07)$ & $26,75( \pm 0,11)$ & $58,59( \pm 0,93)$ & $23,37( \pm 0,33)$ \\
\hline M2 & 42,49 & Agropecuária & $4,06( \pm 0,08)$ & $26,58( \pm 0,09)$ & $57,93( \pm 1,71)$ & $26,54( \pm 0,69)$ \\
\hline M3 & 63,79 & Agropecuária & $4,38( \pm 0,08)$ & $26,52( \pm 0,07)$ & $62,79( \pm 0,88)$ & $20,84( \pm 0,27)$ \\
\hline M4 & 48,67 & Agropecuária & $4,80( \pm 0,10)$ & $27,72( \pm 0,25)$ & $45,01( \pm 4,71)$ & $22,91( \pm 0,89)$ \\
\hline M5 & 113,80 & Agropecuária & $4,66( \pm 0,08)$ & $25,92( \pm 0,04)$ & $71,12( \pm 1,02)$ & $19,34( \pm 0,36)$ \\
\hline M6 & 29,61 & Agropecuária & $4,23( \pm 0,08)$ & $27,60( \pm 0,10)$ & $24,64( \pm 1,04)$ & $26,52( \pm 0,45)$ \\
\hline M7 & 140,72 & Agropecuária & $4,48( \pm 0,10)$ & $26,07( \pm 0,13)$ & $29,92( \pm 1,23)$ & $20,21( \pm 0,47)$ \\
\hline MR1 & 21,76 & Floresta & $4,36( \pm 0,06)$ & $25,17( \pm 0,12)$ & $62,08( \pm 0,89)$ & $29,23( \pm 0,51)$ \\
\hline MR2 & 105,75 & Floresta & $4,41( \pm 0,07)$ & $25,22( \pm 0,14)$ & $80,91( \pm 0,54)$ & $24,31( \pm 0,39)$ \\
\hline G1 & 59,42 & Agropecuária & $4,63( \pm 0,08)$ & $26,33( \pm 0,12)$ & $26,83( \pm 1,48)$ & $23,06( \pm 0,76)$ \\
\hline G2 & 113,81 & Agropecuária & $4,69( \pm 0,08)$ & $28,64( \pm 0,39)$ & $43,43( \pm 2,15)$ & $22,45( \pm 1,38)$ \\
\hline G3 & 63,79 & Agropecuária & $4,44( \pm 0,10)$ & $27,50( \pm 0,16)$ & $24,72( \pm 1,87)$ & $22,43( \pm 1,47)$ \\
\hline G4 & 114,15 & Agropecuária & $4,35( \pm 0,10)$ & $26,09( \pm 0,15)$ & $39,72( \pm 1,05)$ & $21,13( \pm 1,05)$ \\
\hline G5 & 149,16 & Agropecuária & $5,41( \pm 0,11)$ & $26,00( \pm 0,25)$ & $8,43( \pm 1,02)$ & $54,52( \pm 4,09)$ \\
\hline G6 & 33,78 & Agropecuária & $5,01( \pm 0,09)$ & $27,04( \pm 0,28)$ & $28,25( \pm 1,64)$ & $25,10( \pm 0,76)$ \\
\hline G7 & 29,79 & Agropecuária & $4,99( \pm 0,06)$ & $25,55( \pm 0,16)$ & $43,40( \pm 1,69)$ & $24,31( \pm 1,82)$ \\
\hline GR1 & 334,47 & Floresta & $4,66( \pm 0,11)$ & $25,32( \pm 0,15)$ & $63,72( \pm 3,45)$ & $23,76( \pm 0,57)$ \\
\hline GR2 & 229,35 & Floresta & $4,50( \pm 0,07)$ & $25,74( \pm 0,22)$ & $64,42( \pm 1,45)$ & $24,10( \pm 0,52)$ \\
\hline
\end{tabular}

\section{- Potencial Hidrogeniônico}

Os valores máximos e mínimos de $\mathrm{pH}$ nos igarapés das microbacias avaliadas na bacia do rio Marapanim variaram entre 5,356 na M4 no mês de abril de 2010 e 3,446 na M2 no mês de agosto do mesmo ano. O gráfico boxplot mostrado na Figura 2 apresenta a variação dos valores de pH para cada microbacia avaliada. Na M4, o valor médio do $\mathrm{pH}$ de 4,79 $( \pm 0,10)$ foi o mais elevado dentre as microbacias do rio Marapanim, e o que mais divergiu do $\mathrm{pH}$ medido nas microbacias de referência MR1 e MR2, as quais apresentaram, respectivamente, $\mathrm{pH}$ médio de 4,36 $( \pm 0,06)$ e 4,40 $( \pm 0,07)$. 
Figura 2 - Gráficos do tipo boxplot dos valores de pH das microbacias de Marapanim e Guamá, contendo mediana (linha que corta a caixa), média (triângulo), interquartis com intervalo de confiança de 95\% (caixas em tom de cinza), máximos e mínimos (barras verticais), valores extremos (asterístico- outliers), n=12.

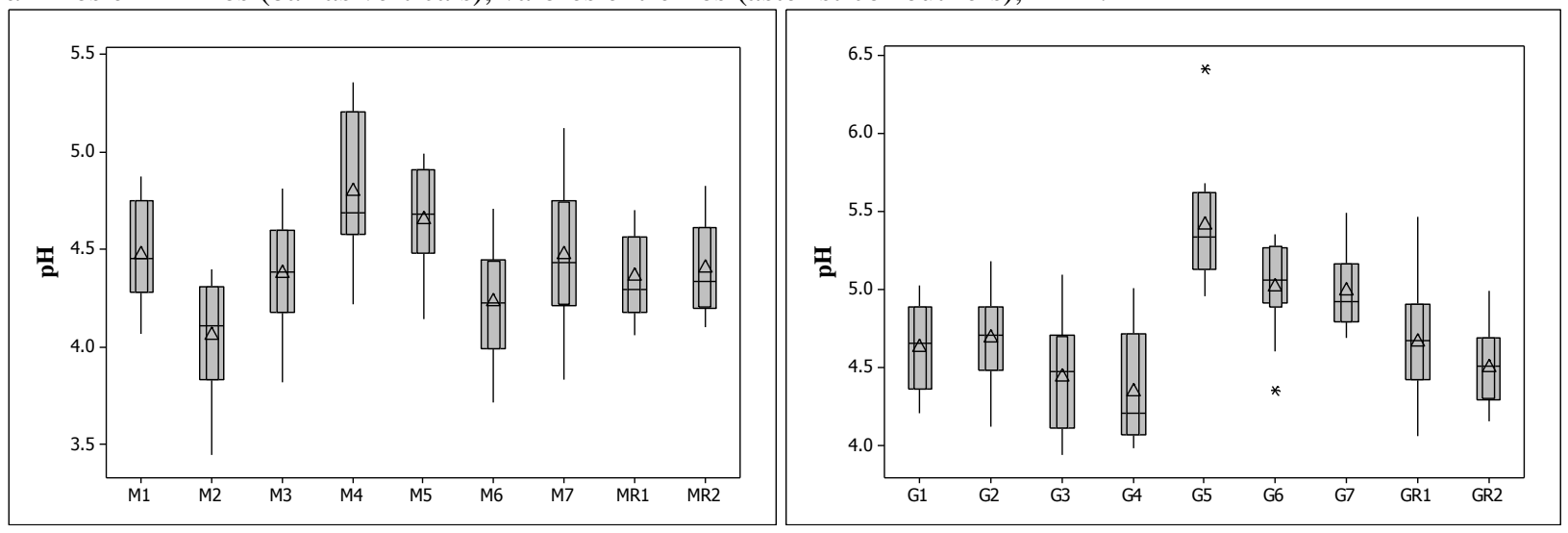

A média de $\mathrm{pH}$, portanto, foi maior na microbacia, cujo percentual de área ocupada por pastagem é maior do que $80 \%$, a M4. Na outra microbacia com percentual de pastagem acima de 80\%, a M6, no entanto, não se observou valores de $\mathrm{pH}$ maiores que aos das microbacias de referência. Isso pode ser explicado, pelo fato de que no trecho amostrado do igarapé da M4 a mata ripária está praticamente ausente, enquanto que na M6, observa-se ainda uma importante presença desta vegetação ciliar. Wickel (2010) sugeriu que nas áreas de pastagem, quando preparadas com uso do fogo, promovem entradas adicionais de cálcio, magnésio e potássio nos seus solos, os quais exportam estes nutrientes via escoamento superficial e sub-superficial até as drenagens de suas bacias o que poderá redundar em tamponamento da acidez das águas pela elevação do $\mathrm{pH}$. Markewitz et al (2001) também observaram a importância das queimadas em pastagens na transferência de cátions dos solos para os igarapés na Amazônia oriental. Além disso, a ausência de mata ripária resulta em menor produção de ácidos orgânicos, responsáveis por acidificar os ambientes terrestre e aquático das bacias.

Já nas microbacias do Rio Guamá, como observado na Tabela 1 e na Figura 2, os valores de $\mathrm{pH}$ tenderam a ser maiores do que em Marapanim. Os igarapés de referência apresentaram valores médios de 4,66 $( \pm 0,11)$ em GR1 e 4,50 $( \pm 0,07)$ em GR2. Esses valores de pH são comparáveis a uma média anual de 4,38 registrada por Figueiredo et al. (2010) no mesmo fragmento florestal, em estudo sobre o efeito do uso da terra sobre os atributos químicos em igarapés de baixa ordem na Amazônia oriental. Houve uma fraca correlação inversa entre o percentual de área de floresta e o pH na bacia do rio Guamá $\left(r_{s}=-0,233\right.$ e $\left.\rho=0,015\right)$. Observando-se a distribuição dos dados das microbacias de Guamá, constata-se que G5 é a microbacia de uso agropecuário com pH mais discrepante em relação as microbacias de referência GR1 e GR2. A área da microbacia ocupada por pastagem em G5 chega a 92,5\% de sua área total, sendo essa a bacia com maior percentual desta classe de uso. 
Também em Guamá tem-se, portanto, uma indicação de que pastagem pode ocasionar aumento de $\mathrm{pH}$ nas águas fluviais, como visto para Marapanim. Na Região Amazônica, rica em solos orgânicos, a tendência é que seus pequenos riachos e as águas subterrâneas retratem a influência dos ácidos orgânicos, apresentando assim baixo pH. Dessa maneira, atividades agropecuárias podem interferir nessa dinâmica da matéria orgânica com consequências sobre os valores de $\mathrm{pH}$ das águas, elevando-os a patamares acima daqueles encontrados em áreas de florestas, devido a processo de preparo de áreas, conforme relatou Sardinha (2006), que constatou pH elevado em áreas de pastagens e atribuiu ao fato do uso de calcário ou das cinzas resultantes das queimadas para a renovação do pasto.

\section{- Condutividade Elétrica}

A Tabela 2 e a Figura 3 mostram os valores médios obtidos neste estudo para a condutividade elétrica (CE). Conforme mostra o gráfico da Figura 3, os maiores valores médios de CE nas microbacias da bacia do rio Marapanim ocorreram na MR1 com 29,23 $\pm 0,51 \mu \mathrm{S}$, seguido pela M2 com 26,54 $\pm 0,69 \mu \mathrm{S}$ e pela M6 com 26,52 $\pm 0,45 \mu \mathrm{S}$. Os maiores valores de CE em M2 e nas microbacias de referência podem ser explicados pela presença de íons $\mathrm{H}^{+}$nessas águas que, segundo Esteves (1998), é o principal preditor da CE em águas ácidas com pH abaixo de 5,00. A análise estatística na escala de bacia demonstrou uma correlação (fraca) e direta entre o percentual de floresta e a CE $\left(r_{s}=0,242\right.$ e $\left.p=0,008\right)$ e de certa forma está coerente com estes resultados e pode explicar os valores mais altos de CE nas microbacias de referência, que detém mais de $85 \%$ de suas áreas de floresta.

Figura 3 - Gráficos do tipo boxplot dos valores de CE das microbacias de Marapanim e Guamá, contendo mediana (linha que corta a caixa), da média (triângulo), interquartis com intervalo de confiança de 95\% (caixas em tom de cinza), máximos e mínimos (barras verticais) e valores extremos (asterístico- outliers), n=12.

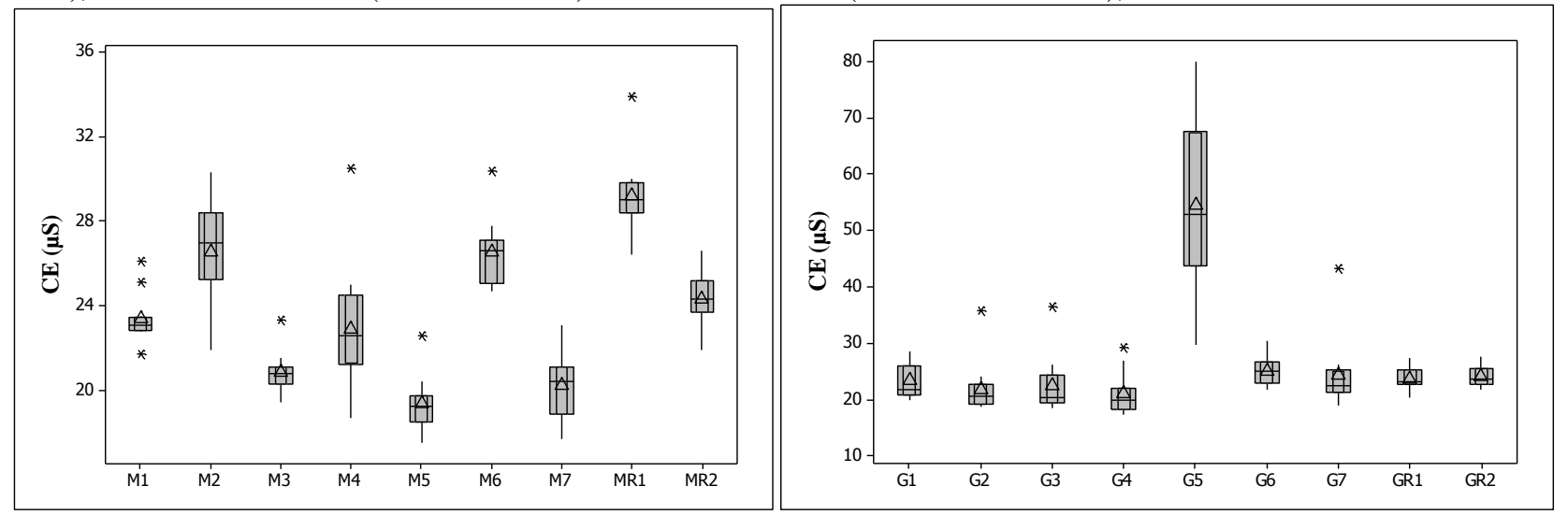

Dentre essas microbacias do Guamá destaca-se a G5 com o maior valor de CE $(54,52 \pm$ $4,09 \mu \mathrm{S})$. Este valor foi duas vezes mais alto quando comparados aos valores das duas microbacias de referência (GR1 e GR2) que apresentaram valores respectivos de 23,76 \pm 0,57 $\mu \mathrm{S}$ e de 24,10 \pm $0,52 \mu \mathrm{S}$. Os valores encontrados em G5 (que detém mais de $90 \%$ de sua área ocupada por pastagem) são comparáveis com o valor de $44 \mu \mathrm{S}$ encontrado por Figueiredo et al. (2010) em 
igarapé com predomínio de pastagem em área com características não muito diferentes de solo, vegetação e uso da terra, em estudo sobre a composição química de águas fluviais na Amazônia oriental. Da mesma forma, os valores encontrados nas referências são bem próximos de 21,30 $\mu \mathrm{S}$, condutividade medida no mesmo trabalho de Figueiredo et al. (2011) em igarapé de referência, também situado no mesmo remanescente de ecossistema florestal do presente estudo. Esta tendência de aumento da CE em área de pastagem também foi confirmada nos estudos de Ballester et al. (2003), que encontraram forte correlação entre o percentual de cobertura de pastagem e alta condutividade na água de igarapé sob influência de pasto na bacia do Rio Ji-Paraná, em Rondônia. Figueiredo et al. (op.cit) testaram modelos estatísticos de efeito de mistura para verificar os efeitos de uso da terra na química da água e constataram que a conversão de floresta para pastagem contribui para o aumento da condutividade na águas desses igarapés.

As áreas de pastagens parecem ter sido determinantes para a elevação dos valores de CE em microbacias ocupadas por áreas maiores de pastagem, e cuja água fluvial não possui elevada acidez. Isto significa que nessas águas há maiores teores de íons dissolvidos, provavelmente originados de maiores entradas de nutrientes dos solos, tanto como material dissolvido quanto como material particulado, via escoamento superficial, cuja magnitude pode ser evidenciada pelos sinais de erosão dos solos, observados nos pastos das microbacias estudadas. Outro fator que pode ter ocasionado esse aumento de condutividade verificado refere-se aos bovinos que costumam visitar as águas dos igarapés, e assim promovem aportes de nutrientes por meio de fezes e urinas.

\section{- Oxigênio Dissolvido}

O gráfico da figura 4 mostra a variação do oxigênio dissolvido (OD) nas águas fluviais das microbacias avaliadas tanto na bacia do rio Marapanim como do Guamá. Em Marapanim, observa-se que os menores percentuais de saturação de OD ocorreram na microbacia M6 com 24,64\% ( $\pm 1,02)$ e na M7 com 29,92\% ( $\pm 1,23)$. Esses valores estão bem abaixo dos valores das microbacias de referência que foram de 62,07\% $( \pm 0,89)$ e 80,90\% $( \pm 0,54)$, em MR1 e MR2, respectivamente. A microbacia $\mathrm{M} 4$, influenciada por pastagem, apresentou média de 45,0\% $( \pm$ 4,71), também bem abaixo dos valores nas microbacias de referência (MR1 e MR2), enquanto as demais microbacias apresentaram OD abaixo das médias de MR1 e MR2, porém bem mais próximos destas. 
Figura 1 - Gráfico do tipo boxplot dos valores de OD das microbacias do Marapanim e do Guamá, contendo mediana (linha que corta a caixa), média (triângulo), interquartis com intervalo de confiança de 95\% (caixas em tom de cinza), máximos e mínimos (barras verticais) e valores extremos (asterístico- outliers), $\mathrm{n}=12$.

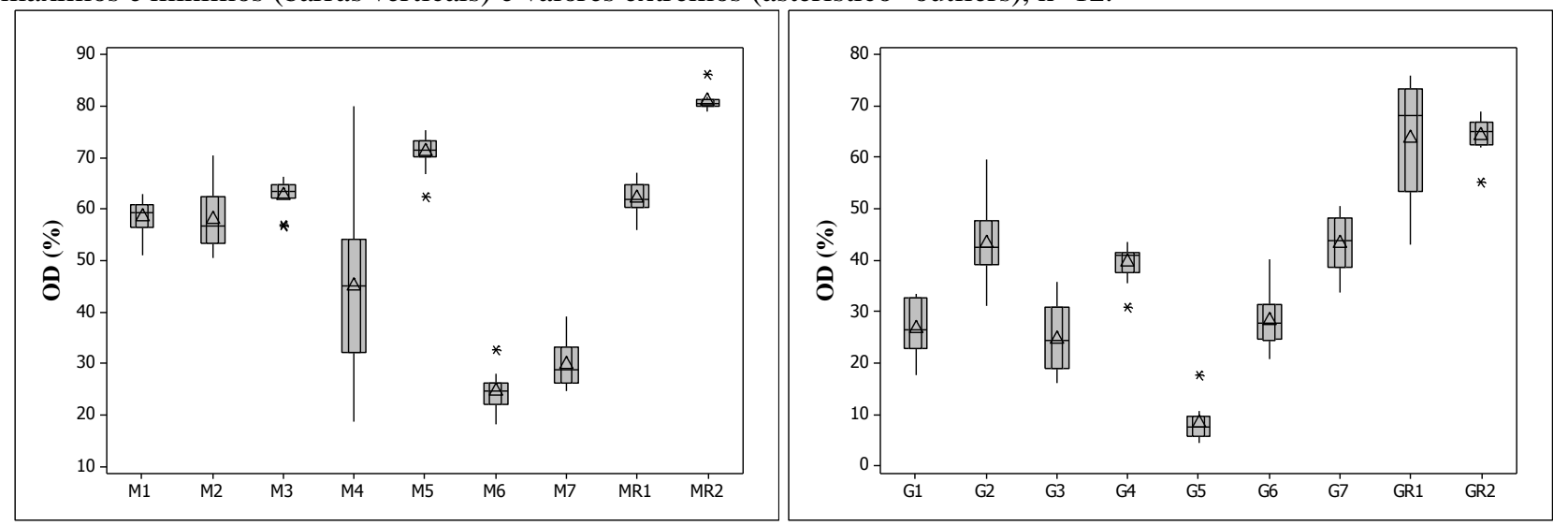

Dentre as microbacias de Marapanim, a do igarapé Ubim (M6) como já indicado, apresentou o menor percentual de saturação de OD em suas águas, o que pode estar relacionado ao fato de se tratar de nascente que naturalmente tendem a apresentar baixas concentrações de OD, ou devido ao consumo de OD através da respiração de macrófitas aquáticas presentes nessa nascente ou pelo consumo de OD como consequência de processos bioquímicos como a nitrificação (FIORUCCI e BENEDETTI-FILHO, 2005).

A análise de correlação entre OD e o percentual de floresta na bacia de Marapanim, foi positiva e significativa $\left(r_{\mathrm{s}}=0,507\right.$ e $\left.\rho=0,000\right)$, mas foi inversa com o percentual de pastagem $\left(\mathrm{r}_{\mathrm{s}}=\right.$ $0,470$ e $\rho=0,000)$, percentual de cultivo agrícola $\left(r_{s}=-0,383\right.$ e $\left.\rho=0,000\right)$ e percentual de solo exposto $\left(\mathrm{r}_{\mathrm{s}}=-0,475\right.$ e $\left.\rho=0,000\right)$. Estes resultados estatísticos denotam que a conversão de florestas para a implantação de atividades agropecuárias pode interferir na concentração de OD nas águas dos igarapés.

Para os igarapés da bacia do Guamá, destaca-se o percentual de saturação de OD bem menor em G5, além de baixo OD em G3, G1 e G6. Com mais de 90\% de sua área coberta por pastagem, a G5 foi dentre as microbacias deste estudo como um todo a que apresentou níveis mais críticos de percentual de OD com média de 8,43\% ( $\pm 1,02)$. Este valor é mais de 8 vezes menor quando comparado as microbacias de referência (GR1 e GR2) que apresentaram valores de 63,72 ( \pm $3,45)$ e $64,42 \%( \pm 1,45)$. Além da G5, merecem destaque também as microbacias do igarapés Divisa (G3) com percentual de OD de 24,72 $\pm 1,87 \%$, do Seringa (G1) com 26,83 $\pm 1,48 \%$ e do Chico Lopes (G6) com 28,25 $\pm 1,64 \%$, as quais apresentaram valores de OD abaixo das médias das microbacias de referência.

Vários fatores podem contribuir para este baixo percentual de saturação de OD observados nas microbacias citadas, por exemplo: a presença de vegetação aquática (G3, G5 e na G6) a montante do ponto de medição, e; no caso específico do igarapé da microbacia G5, a presença frequente de gado em suas águas, promovendo o aporte de material orgânico por meio de fezes e 
urinas, que são decompostos e assim reduzem a nível crítico as concentrações de oxigênio. Neill et al (2001), em estudo de bacias no Estado de Rondônia, também associou a conversão de floresta em pastagem à redução do OD nas águas de igarapés, medindo nos igarapés em área de floresta valores de percentual de OD próximo à saturação, enquanto que nos igarapés em área de pastagens o valor médio foi menor do que $20 \%$.

$\mathrm{Na}$ bacia do rio Guamá, o percentual de pastagem, bem como o percentual de floresta foram fortemente correlacionados com o OD, sendo que houve uma correlação inversa com a pastagem $\left(r_{\mathrm{s}}=-0,885\right.$ e $\left.\rho=0,000\right)$, com solo exposto $\left(r_{\mathrm{s}}=-0,533\right.$ e $\left.\rho=0,000\right)$ e com várzea $\left(\mathrm{r}_{\mathrm{s}}=-\right.$ $0,505$ e $\rho=0,000)$, mas com a floresta a correlação foi direta $\left(r_{s}=0,724\right.$ e $\left.\rho=0,000\right)$. Essa relação estatística confirma a interpretação de resultados apresentadas neste estudo, onde nas microbacias florestadas observaram-se maiores concentrações de OD, enquanto que nas pastagens o inverso foi observado.

\section{- Temperatura}

O gráfico da Figura 5 mostra os valores de temperatura nas microbacias da bacia do rio Marapanim e do Guamá. As maiores temperaturas ocorreram nas águas dos igarapés das microbacias M4 e M6. As duas microbacias de referências (MR1 e MR2) apresentaram as menores temperaturas com valores respectivos de $25,17^{\circ} \mathrm{C}( \pm 0,12)$ e $25,22^{\circ} \mathrm{C}( \pm 0,14)$.

Figura 5 - Gráficos do tipo boxplot dos valores de T $\left({ }^{\circ} \mathrm{C}\right)$ das microbacias do Marapanim e Guamá, contendo mediana (linha que corta a caixa), média (triângulo), Interquartis com intervalo de confiança de 95\% (caixas em tom de cinza), máximos e mínimos (barras verticais) e valores extremos (asterístico- outliers), n=12.
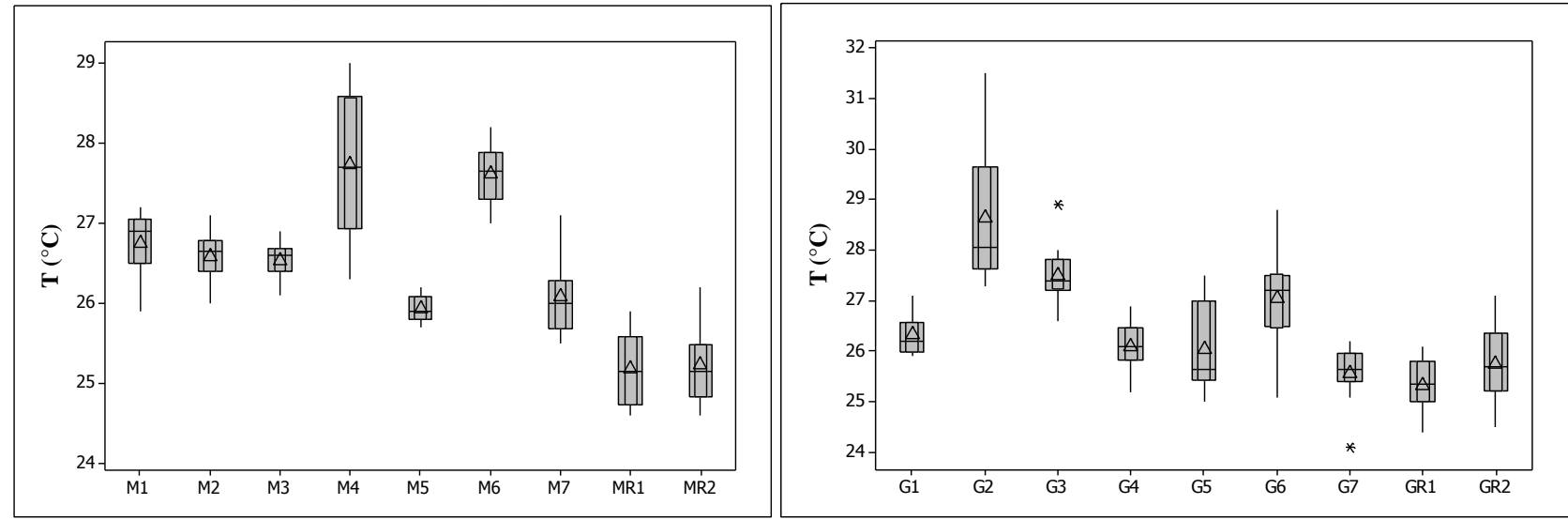

Da mesma forma que em Marapanim, na bacia do rio Guamá destaca-se a tendência de menores temperaturas nas microbacias de referência, que a apresentaram $25,32 \pm 0,15{ }^{\circ} \mathrm{C}$ e $25,74 \pm$ $0,22{ }^{\circ} \mathrm{C}$, em GR1 e GR2 respectivamente. Há de se ressaltar que uma conclusão mais contundente sobre as diferenças entre as temperaturas medidas nos diferentes igarapés fica comprometida em função dessas medições haverem sido realizadas em horários diferentes, pois sabe-se que medidas feitas em horário de pleno sol serão naturalmente mais elevadas. 
No entanto, é fato que as maiores temperaturas, que ocorrem em igarapés ocupados por maiores áreas de pastagem, podem estar sendo determinadas pela maior exposição ao sol do leito dos igarapés ao cruzarem pastos desprovidos de floresta ripária. Além disso, a vegetação de áreas referências ou da G7 com sua mata de igapó, promove a redução da incidência de radiação solar sobre as águas fluviais, e assim contribuem para manutenção de temperaturas amenas. Swank e Johnson (1994) citam alguns estudos em microbacias experimentais no leste dos Estados Unidos, onde a remoção da copa de floresta adjacente aos cursos d'água aumentou a incidência de radiação solar na superfície da água e consequentemente houve aumento de temperatura. Figueiredo et al. (2010), estudando pequenas bacias em região próxima à Mãe do Rio, também observou aumento de temperatura associada a pastagem e decréscimo associado a floresta.

Em geral, os igarapés de Marapanim (M1 a M7) apresentaram menores temperaturas quando comparadas aos igarapés da bacia do rio Guamá (G1 a G7), o que pode está relacionada ao predomínio de fragmentos de floresta ripária ainda preservada nestes igarapés de Marapanim, o que não ocorre nos igarapés do Guamá, com exceção da G7.

\section{CONCLUSÃO}

Verificou-se uma forte influência dos sistemas agrícolas, especialmente as pastagens, sobre os parâmetros físico-químicos mensurados, com redução do oxigênio dissolvido e aumento da temperatura, do $\mathrm{pH}$ e da condutividade elétrica nas águas fluviais das microbacias avaliadas. Por outro lado, nas microbacias florestadas, com baixa interferência antrópica, observaram-se maiores teores de oxigênio dissolvido, temperaturas amenas e valores baixos de $\mathrm{pH}$ e condutividade elétrica, o que demonstra uma melhor qualidade da água nesses sistemas fluviais.

Pelos resultados do presente estudo infere-se que a presença da vegetação ripária possui grande potencial para mitigar os impactos dos sistemas agrícolas sobre os recursos hídricos. Portanto, a conservação e recuperação dessa vegetação se revelam como ferramentas importantes para a gestão de bacias hidrográficas e manutenção da qualidade da água e recomenda-se que no âmbito rural seja também realizada a substituição de práticas que utilizam o fogo por técnicas mais sustentáveis de produção agropecuária.

Por fim sugere-se que, para a gestão local de bacias hidrográficas, seja realizado o monitoramento das águas fluviais por meio de medição dos parâmetros físico-químicos aqui avaliados, que se mostraram como bons indicadores para a avaliação da sustentabilidade ambiental dos sistemas agropecuários de produção praticados nas microbacias monitoradas. 


\section{REFERÊNCIAS BIBLIOGRÁFICAS}

BALLESTER, M.V.R. et al. A remote sensing/GIS-based physical template to understand the biogeochemistry of the Ji-Paraná river basin (Western Amazônia). Remote Sensing of Environment, v. 87 p.429-445. 2003.

CETESB, Companhia de Tecnologia de Saneamento Ambiental. Análise físico-química das águas. Normalização técnica NT-07, São Paulo, 1978, 340 p.

DI LUZIO, M. et al. ArcView interface for SWAT2000: user's guide. Texas Water Resources Institute Report TR-193, Temple, 2002, 351p.

FIGUEIREDO, R.O. et al. Land-use effects on the chemical attributes of low-order streams in the eastern Amazon. Journal of Geophysical Research, v.115, p.01-14. 2010.

FIORUCCI, A.R.; BENEDETTI-FILHO, E. A importância do oxigênio dissolvido em ecossistemas aquáticos. Química e Sociedade, n. 22, p.10-16, 2005.

MARKEWITZ, M., et al. Control of cation concentrations in stream waters by surface soil processes in an Amazonian watershed, Nature, 410, 802-805, 2001.

MOREIRA, A.M. Estudo comparativo do uso da terra em unidades de produção familiar no Nordeste Paraense. 87f. Dissertação (mestrado em ciências ambientais), Universidade Federal do Pará, Belém-PA, 2008.

NEILL, C. et al, Deforestation for pastures alters nitrogen and phosphorus in small Amazonian streams. Ecological Applications, v.11, n.6, p.1817-1826, 2001.

SARDINHA, A.S. Avaliação dos efeitos da mata ciliar sobre os fluxos hidrogeoquímicos em área de pastagem: caso das bacias hidrográficas dos igarapés do Sete e Pajeú-Paragominas-PA. 126f. Dissertação (mestrado em geologia e geoquímica) - Universidade Federal do Pará, Belém-PA, 2006.

SALIMON, C.I. et al. Mudança de cobertura da terra e fluxo de $\mathrm{CO}_{2}$ do solo para a atmosfera na Amazônia Sul Oriental. In. SIMPÓSIO BRASILEIRO DE SENSORIAMENTO REMOTO, 11., 2003, Belo Horizonte-MG, Anais... São José dos Campos:SP : INPE, p. 699-705, 2003.

SWANK, W.T.; JOHNSON, C.E. Small Catchment Research in the Evaluation and Development of Forest Management Practices. In: MOLDAN, B.; CERNY, J. (Ed.). Biogeochemistry of small catchments: a tool for environmental research. SCOPE, p. 382-408, New York: John Wiley and Sons, 1994, cap. 17, n.51.

WATRIN, O.S.; GERHARD, P.; MACIEL, M.N. M. Dinâmica de uso da terra e configuração da paisagem em antigas áreas de colonização de base familiar, no Nordeste do Estado do Pará. Geografia, v. 34, n. 3, p. 455-472, Rio Claro, 2009.

WICKEL, B.A.J. Water and nutrient dynamics of a humid tropical watershed in Eastern Amazonia. Bonn: Center of Development Research-University of Bonn. 135p. 2004. (Ecology and Development Series, n. 21). 